\title{
EFFECTS OF PLYOMETRIC TRAINING PROGRAM ON SPEED AND AGILITY IN YOUNG CRICKETERS
}

1. Assistant Director Sports. Department of Sports Sciences, Islamia University, Bahalpur Pakistan

2. Director Sports. Islamabad Model College for Boys, F$7 / 3$, Islamabad Pakistan

3. Lecturer. Department of Sport Sciences, Abdul Wali Khan University, Mardan Pakistan

4. Lecturer. College of Physical Therapy. Northwest Institute of Health Sciences, Peshawar Pakistan

5. Rehab Officer. Helping Hand Institute of Rehabilitation Sciences, Mansehra. Pakistan

\begin{tabular}{|c|}
\hline $\begin{array}{c}\text { Correspondence } \\
\text { Naveed Ashraf } \\
\text { Assistant Director Sports. Department of Sports Sciences, } \\
\text { Islamia University, Bahawalpur Pakistan } \\
\text { E-mail: } \underline{\text { needo300@gmail.com }}\end{array}$ \\
\hline $\begin{array}{c}\text { Received on: } 23-04-2019 \\
\text { Revision on: } 10-05-2019 \\
\text { Published on: } 30-06-2019\end{array}$ \\
\hline $\begin{array}{l}\text { Citation } \\
\text { Ashraf } \mathrm{N} \text {, Ismat } \mathrm{U} \text {, Shah } \mathrm{M} \text {, Hussain SA, Batool U. } \\
\text { Effects of plyometric training program on speed } \\
\text { and agility in young cricketers. T Rehabili. J. } \\
\text { 2019:03(01);85-89 } \\
\text { soi: } 21-2017 / \text { re-trivol03iss01p85 }\end{array}$ \\
\hline
\end{tabular}

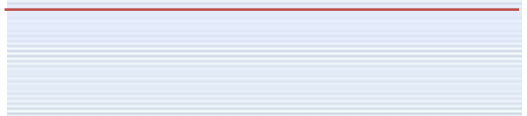

\begin{abstract}
Naveed Ashraf ${ }^{1}$ : Analysis \& interpretation of data, writing; Revised and Accountable for all aspects
Ismat Ullah ${ }^{2}$ : Analysis \& interpretation of data, writing; Revised and Accountable for all aspects

Muhammad Shah ${ }^{3}$ : Analysis \& interpretation of data, writing; Revised and Accountable for all aspects

Syed Alamdar Hussain ${ }^{4}$ : Writing; Revised and Accountable for all aspects

Unaiza Batool ${ }^{5}$ : Writing; Revised and Accountable for all aspects

ABSTRACT

Objective: to evaluate the effects of plyometric training program on speed and agility of young Pakistani cricketers. Material \& Methods: A Randomized Controlled Trail (NCT03830632) was conducted in Fitdiction Gym Islamabad after the approval from the competent authority. Non probability convenient sampling technique was used to collect sample. The $n=40$ sample size was randomly allocated in two groups the plyometric training group and traditional training group, with 20 participants in each group. The male professional club cricketers with age between 14-24 years old from Islamabad were included after written informed consent. Speed was measured through 30 meter sprint test and T-Test to check the agility of cricketers. Repeated measure ANOVA was used to analyze with-in group changes in both groups and independent t-test was use to compare the effects of both training programs. The significance level was set at $p<0.05$. Results: The mean age and BMI of cricketers were $18 \pm 1.97$ years and $33.40 \pm 21.23$ respectively. While comparing both groups, no significant difference observed throughout training session of agility and speed time $(p>0.05)$. But the mean difference of agility and speed time of both groups was increased throughout training session. Conclusion: The results Indicated that both plyometric and traditional training improved speed and agility in young cricketers at the end of study. While comparing with traditional training, no statistically significance difference found between both groups. But when considering mean difference of time in speed and agility practical significance was observed.

Keyword: Plyometrics, agility, speed, physical fitness, cricket.
\end{abstract}

\section{INTRODUCTION}

Cricket is a team game and cricketers have to performed different role as a bowler, fielder or as batsman. In a same game that consists of intermittent activity during which players are required to repeatedly perform striding, sprinting, turning and jumping. Which place considerable demands on the physiological and neuromuscular system. ${ }^{1-4}$ Therefore, lower limb muscles ability to produce power is an important component of fitness for cricketers. ${ }^{5}$ Plyometric training has been an effective method for the improvement of agility, sprinting, and jumping ability ${ }^{6-8}$ and it has also been reported to Improve running economy, joint stability, increased joint awareness and overall proprioception and decrease the severity of knee injuries. ${ }^{9,10}$

In the Plyometric exercise involves starting, stopping, and change of movement directions which contribute to agility development. ${ }^{11}$ The athletes use plyometric training techniques in many sports to improve explosive power and body strength. ${ }^{12}$ In sport, many researchers ${ }^{11,13-15}$ found that the plyometric training is effects in developing agility. They also found that plyometrics also helps to improve strength and speed not only breaks the monotony of training.

Cricket is the most popular sports in Pakistan, but there is no concept of fitness among the young cricketers at domestic level. Every cricket player focus on skill related fitness whereas only skill related fitness is not enough to perform at high level. The Trainers in Pakistan are still using traditional trainings program due to lack of knowledge or trainings. There is no organized plyometric training plan. While internationally plyometric training is essential part of games to increase the speed and agility in players. In Pakistan no study was found on plyometric training among young cricketers. This study was conducted to evaluate the effects of plyometric training program on speed and agility of young Pakistani cricketers.

\section{METERIAL \& METHODS}

A Randomized Controlled Trail (NCT03830632) was conducted in Fitdiction Gym Islamabad F 8 Markaz

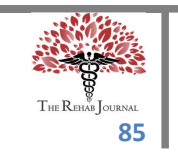


after the approval from the competent authority. The study was completed in 6 Months from January 2016 - June 2016. Non probability convenient sampling technique was used to collect sample. The $\mathrm{n}=40$ sample size was randomly allocated in two groups with 20 participants in each group.(Figure 1) The male professional club cricketers with age between 14-24 years old from Islamabad were included after informed consent.

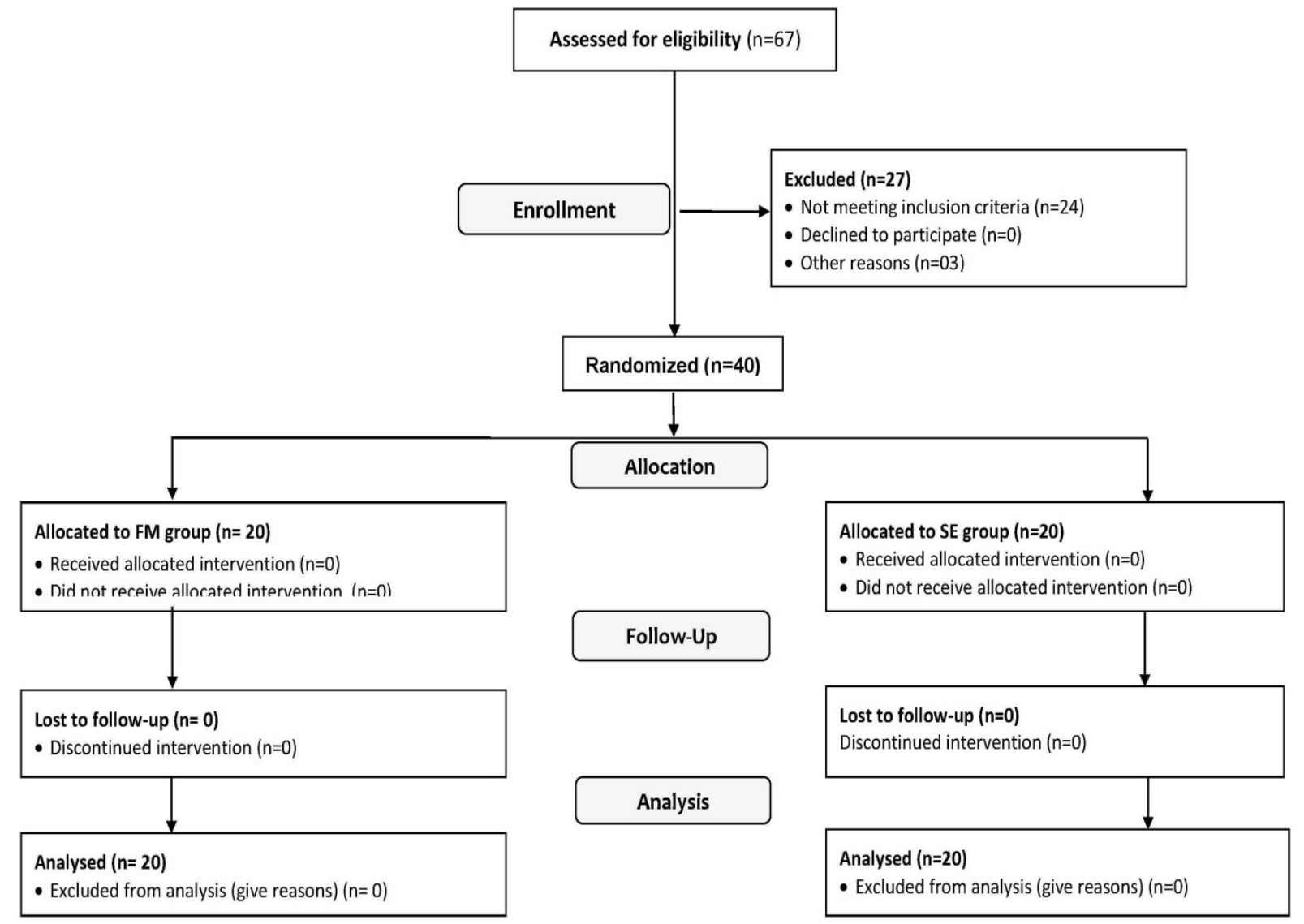

Figure 1: CONSORT diagram

The plyometric training group participated in 8-week training program performing a variety of plyometric exercises designed for the lower extremity. (Table 1) While traditional training program group performed Aerobic Training - A minimum of two low-intensity sessions a week consisting of 1 hour running and Shuttle Sprints - Placed two cones roughly 25 yards apart. The cricketers were asked to sprint as fast as back and forth between the cones 12 times within one minute for a total of six round-trips. After that rest for 2-3 minutes, then repeat once. All subjects were instructed not to start any lower extremity strengthening programs during the 8- week period and to only perform activities of normal daily living. Speed was measured through 30 meter sprint test, involves running a single maximum sprint over 30 meters, with the time recorded and T-Test to check the agility of cricketers with movements, like left, right, forward and backward. Front foot must be on or behind the starting line. The data was analyzed at zero day, $4^{\text {th }}$ week and then after 8 week. Repeated measure ANOVA was used to analyze with-in group changes in both groups and independent t-test was use to compare the effects of both training programs. The significance level was set at $p<0.05$. SPSS Ver. 21 was used for data analysis. 
Table 1: Detail description of 8 week plyometric training

\begin{tabular}{|c|c|c|c|}
\hline Weeks & Plyometric exercises & Repetitions \& Sets & Intensity \\
\hline \multirow{3}{*}{$\begin{array}{l}1^{\text {st }} \text { week } \\
\text { (80 foot contacts) }\end{array}$} & Ankle hops & $16 \times 2$ & \multirow{3}{*}{ Low } \\
\hline & Box jump & $8 \times 3$ & \\
\hline & Jump squats & $8 \times 3$ & \\
\hline \multirow{3}{*}{$\begin{array}{l}2^{\text {nd }} \text { week } \\
\text { (90 foot contacts) }\end{array}$} & Ankle hops & $15 \times 2$ & Low \\
\hline & Box jump & $10 \times 3$ & \multirow{2}{*}{ Medium } \\
\hline & Jump squats & $10 \times 3$ & \\
\hline \multirow{4}{*}{$\begin{array}{l}3^{\text {rd }} \text { week } \\
\text { (100 foot contacts) }\end{array}$} & Ankle hops & $15 \times 2$ & Low \\
\hline & Box jump & $10 \times 3$ & \multirow{3}{*}{ Medium } \\
\hline & Jump squats & $10 \times 3$ & \\
\hline & Plyometric step-ups & $10 \times 2$ & \\
\hline \multirow{5}{*}{$\begin{array}{l}4^{\text {th }} \text { week } \\
\text { (110 foot contacts) }\end{array}$} & Ankle hops & $15 \times 2$ & Low \\
\hline & Box jump & $10 \times 3$ & \multirow{4}{*}{ Medium } \\
\hline & Jump squats & $8 \times 3$ & \\
\hline & Plyometric step-ups & $8 \times 3$ & \\
\hline & Depth jumps & $6 \times 2$ & \\
\hline \multirow{5}{*}{$\begin{array}{l}5^{\text {th }} \text { week } \\
\text { (120 foot contacts) }\end{array}$} & Ankle hops & $15 \times 2$ & Low \\
\hline & Box jump & $10 \times 3$ & \multirow{4}{*}{ Medium } \\
\hline & Jump squats & $8 \times 3$ & \\
\hline & Depth jumps & $8 \times 2$ & \\
\hline & Alternate lunge jumps & $10 \times 2$ & \\
\hline \multirow{5}{*}{$\begin{array}{l}6^{\text {th }} \text { week } \\
\text { (130 foot contacts) }\end{array}$} & Ankle hops & $15 \times 2$ & Low \\
\hline & Box jump & $10 \times 2$ & Medium \\
\hline & Jump squats & $10 \times 3$ & \multirow{3}{*}{ High } \\
\hline & Depth jumps & $8 \times 3$ & \\
\hline & Alternate lunge jumps & $13 \times 2$ & \\
\hline \multirow{5}{*}{$\begin{array}{l}7^{\text {th }} \text { week } \\
\text { (140 foot contacts) }\end{array}$} & Ankle hops & $15 \times 2$ & Low \\
\hline & Box jump & $10 \times 2$ & Medium \\
\hline & Jump squats & $10 \times 3$ & \multirow{3}{*}{ High } \\
\hline & Depth jumps & $8 \times 3$ & \\
\hline & Alternate lunge jumps & $15 \times 2$ & \\
\hline \multirow{5}{*}{$\begin{array}{l}8^{\text {th }} \text { week } \\
\text { (120 foot contacts) }\end{array}$} & Ankle hops & $15 \times 2$ & Low \\
\hline & Box jump & $10 \times 2$ & \multirow{3}{*}{ Medium } \\
\hline & Jump squats & $8 \times 3$ & \\
\hline & Depth jumps & $8 \times 2$ & \\
\hline & Alternate lunge jumps & $15 \times 2$ & High \\
\hline
\end{tabular}

\section{RESULTS}

The mean age of cricketers was $18 \pm 1.97$ years. In plyometric and traditional training group mean age was $18.05 \pm 2.18$ and $17.95 \pm 1.79$ respectively. The average BMI of all participants was $33.40 \pm 21.23$ (Plyometric $=21.98 \pm 3.81, \quad$ Traditional $=20.49 \pm 3.87$ ). The average calories intake in all participants was $2437.50 \pm 323.98$

(Plyometric $=2575 \pm 293.57$,

Traditional $=2300 \pm 299.12$ ).

The results showed that mean agility and speed test time in plyometric training group reduced significantly throughout session and $(F(1.35$,
$25.80)=35.21, \quad p<0.001$ ) respectively. But in traditional training group agility time was significantly increased $(F(1.52,29.02)=5.87$, $p=0.012)$. Initial 4 weeks $(11.93 \pm 0.79$ ver. $12.03 \pm 0.80, p=0.013)$ and throughout training session (11.93 \pm 0.79 ver. $11.99 \pm 0.78, \quad p=0.029$ ) showed significant increase in agility time. After 4th week to 8th week insignificant reduction in agility time was observed $(12.03 \pm 0.80$ ver. $11.99 \pm 0.78$, $p=0.128$ ). The $30 \mathrm{~m}$ sprint test showed that speed time was not significant differed throughout the training session $\{F(1.08,20.52)=1.77, p=1.99\}$. But

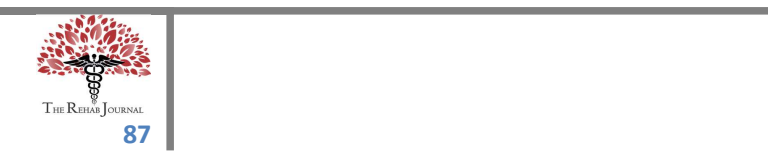


Post hoc tests using the Bonferroni correction revealed that initial 4 week showed significant increase $(5.22 \pm 0.34$ ver. $5.26 \pm 0.34, p<0.001)$ in speed time but after 4 week-8 week $(5.26 \pm 0.34$ ver.
5.27 $\pm 0.37, \quad p=0.654)$ and throughout $(5.22 \pm 0.345 .27 \pm 0.37, \quad p=0.138)$ training did not showed significant changes. (table 2)

Table 2: within-group changes of agility and speed time

\begin{tabular}{|c|c|c|c|c|c|c|c|}
\hline & \multirow{2}{*}{ Sessions } & \multicolumn{3}{|c|}{ Plyometric $(n=20)$} & \multicolumn{3}{|c|}{ Traditional } \\
\hline & & Mean $\pm S D$ & MD & $p$-value & Mean \pm SD & MD & p-value \\
\hline & 0 day & $11.81 \pm 0.87$ & $0.12^{\mathrm{a}}$ & $<0.001^{a}$ & $11.93 \pm 0.79$ & $-0.10^{a}$ & $0.013^{a}$ \\
\hline \multirow[t]{2}{*}{ Agility (T-Test) } & $4^{\text {th }}$ week & $11.68 \pm 0.83$ & $0.09^{b}$ & $<0.001^{b}$ & $12.03 \pm 0.80$ & $0.04^{b}$ & $0.128^{b}$ \\
\hline & $8^{\text {th }}$ week & $11.59 \pm 0.83$ & $0.22^{c}$ & $<0.001^{\mathrm{c}}$ & $11.99 \pm 0.78$ & $-0.06^{c}$ & $0.029^{c}$ \\
\hline \multirow{3}{*}{ 30m Sprint Test } & 0 day & $5.25 \pm 0.31$ & $0.08^{a}$ & $<0.001^{a}$ & $5.22 \pm 0.34$ & $-0.03^{\mathrm{a}}$ & $<0.001^{\mathrm{a}}$ \\
\hline & $4^{\text {th }}$ week & $5.17 \pm 0.31$ & $0.07^{b}$ & $<0.001^{b}$ & $5.26 \pm 0.34$ & $-0.01^{b}$ & $0.654^{b}$ \\
\hline & $8^{\text {th }}$ week & $5.10 \pm 0.29$ & $0.15^{c}$ & $<0.001^{\mathrm{c}}$ & $5.27 \pm 0.37$ & $-0.05^{c}$ & $0.138^{c}$ \\
\hline
\end{tabular}

${ }^{a} 0$ day \& $4^{\text {th }},{ }^{b} 4^{\text {th }} \& 8^{\text {th }}$ week, ${ }^{c} 0$ day $\& 8^{\text {th }}$ week

While comparing both groups, there was no significant difference was observed throughout training session regarding agility and speed time ( $p>0.05)$. But the mean difference of agility and speed time of both groups was increased throughout training session.

Table 3: between-group comparison of agility \& speed

\begin{tabular}{|c|c|c|c|c|c|}
\hline & \multirow{2}{*}{ Sessions } & Plyometric & Traditional & \multirow{2}{*}{ MD } & \multirow{2}{*}{ p-value } \\
\hline & & Mean士SD & Mean $\pm S D$ & & \\
\hline \multirow{3}{*}{ Agility (T-Test) } & 0 day & $11.81 \pm 0.87$ & $11.93 \pm 0.79$ & -0.12 & 0.669 \\
\hline & $4^{\text {th }}$ week & $11.68 \pm 0.83$ & $12.03 \pm 0.80$ & -0.34 & 0.191 \\
\hline & $8^{\text {th }}$ week & $11.59 \pm 0.83$ & $11.99 \pm 0.78$ & -0.40 & 0.123 \\
\hline \multirow{3}{*}{$30 \mathrm{~m}$ Sprint Test } & 0 day & $5.25 \pm 0.31$ & $5.22 \pm 0.34$ & 0.02 & 0.782 \\
\hline & $4^{\text {th }}$ week & $5.17 \pm 0.31$ & $5.26 \pm 0.34$ & -0.09 & 0.398 \\
\hline & $8^{\text {th }}$ week & $5.10 \pm 0.29$ & $5.27 \pm 0.37$ & -0.17 & 0.099 \\
\hline
\end{tabular}

\section{DISCUSSION}

This study was conducted to define the effects of 8week plyometric training programme on speed and agility in young cricketers'. The both groups statically showed improvement in agility but plyometric group also showed statistical significant improvement in speed. While comparing both groups no significant difference was observed between groups.

The plyometric training not only makes advancement in the speed and agility but also helps in building up the power and strength of the body. The increase in speed and agility is helpful for cricketers who perform in batting, fielding and bowling. Earlier studies of plyometric training have speculated that gains were enhanced by motor unit recruitment patters. ${ }^{15}$ Usually when an athlete reacts or responds as a result of better coordination between the proprioceptive feedback and the CNS signal the, neural adaptations occur. However, it couldn't conclude if neural adaptations occur via improved enabling of neural impulses to the spinal cord or synchronous dismissal of the motor neurons. ${ }^{16}$

In current study, improvement in subjects who experienced plyometric training significantly on both the T-test and 30 meter test was recorded. A positive cause and effect relationship was found between plyometric training and enhancements of both speed tests and agility. This improvement is beneficial for young cricketers who require fast movements while execution of their sport related task i.e agility and speed besides it too support results from other studies. A study on tennis players used a T-test and dot drill test to conclude speed and agility ${ }^{17}$ The players showed positive progression in becoming quicker and more agile; empowering them to catch up with more balls and show more efficacies in the tennis play. Renfro worked on agility thru T-test with plyometric training. ${ }^{18}$ whereas 
Robinson and Owens used horizontal, vertical and lateral plyometric jumps demonstrating improvements in agility. ${ }^{19}$ Many literatures using plyometric training have shown significant uplifts in atypical areas of various sports, comprising of block starts in swimming ${ }^{20}$ vertical jump in basketball ${ }^{21}$ power enhancement in hockey ${ }^{22}$ increase in long distance running economy ${ }^{23}$ and the golf club head speed. $^{24}$

The results of the current study have significant practical implication signifying that an eight-week plyometric training merged into a conventional cricket training program may clue a better developments in several explosive actions than cricket training only; even with a lowest training regularity of one session/week. Evidence shows that the capability to uphold or improve various explosive features of physical fitness while the in-season period is of vital importance due to the partial time offered for specific training. However, it should be stated that we did not spot major alterations among groups, post-training measurements.

The lack of variance among plyometric groups and conventional cricket group that we perceived may be somewhat credited to the training stimulus (i.e. training frequency, total training sessions etc.) made in this study. Thus, a plyometric training inducement comprised of one session/week which is adequate to preserve or somewhat improve jumping performance, agility and speed in cricket players during the in-season. For more improvements in jumping performance, agility and speed in young cricket players during the in-season period, fitness professionals and coaches need to achieve more specialized training interventions.

\section{CONCLUSION}

The results Indicated that both plyometric and traditional training improved speed and agility young cricketers at the end of study. While comparing with traditional training, no statistically significance difference found between both groups. But when considering mean difference of time in speed test and agility test practical significance was observed.

\section{REFERENCES}

1. Johnstone JA, Ford PA. Physiologic profile of professional cricketers. J Strength Cond Res. 2010;24(11):2900-7

2. Bartlett RM. The science and medicine of cricket: an overview and update. J Sports Sci. 2003;21(9):733-52.

3. Michael Bailey, Stephen R. Clarke. Predicting the Match Outcome in One Day International Cricket Matches, while the Game is in Progress. J Sports Sci Med. 2006: 5(4): 480487.

4. G. Lockie Robert, Samuel J. Callaghan, Matthew D. Jeffriess. Acceleration Kinematics in Cricketers: Implications for Performance in the Field. J Sports Sci Med. 2014 Jan; 13(1): 128-136.

5. Ford P, De Ste Croix M, Lloyd R, Meyers R, Moosavi M, Oliver J, et al. The long-term athlete development model: Physiological evidence and application. J Sports Sci. 2011;29(4):389-402

6. Asadi A. Effects of in-season short-term plyometric training on jumping and agility performance of basketball players. Sport Sci Health. 2013;9(3):133-7.

7. Thomas K, French D, Hayes PR. The effect of two plyometric training techniques on muscular power and agility in youth soccer players. J Strength Cond Res. 2009;23(1):332-5.

8. Jovanovic M, Sporis G, Omrcen D, Fiorentini F. Effects of speed, agility, quickness training method on power performance in elite soccer players. J Strength Cond Res. 2011;25(5):1285-92.

9. Mandelbaum BR, Silvers HJ, Watanabe DS, Knarr JF, Thomas SD, Griffin LY, et al. Effectiveness of a neuromuscular and proprioceptive training program in preventing anterior cruciate ligament injuries in female athletes: 2-year follow-up. Am J Sports Med. 2005;33(7):1003-10.

10. Hewett TE, Paterno MV, Myer GD. Strategies for enhancing proprioception and neuromuscular control of the knee. Clin Orthop Relat Res. 2002 Sep;(402):76-94

11. Miller MG, Herniman JJ, Ricard MD, Cheatham CC, Michael TJ. The effects of a 6-week plyometric training program on agility. J Sports Sci Med. 2006;5(3):459-465.

12. Sáez de Villarreal $E$, Requena B, Cronin JB. The effects of plyometric training on sprint performance: a meta-analysis. J Strength Cond Res. 2012;26(2):575-84.

13. Heang $\mathrm{L}$, Hoe WE, Quin CK, Yin LH. Effect of plyometric training on the agility of students enrolled in required college badminton programme. Int J App Sports Sci. 2012;24(1):18-24.

14. Bal BS, Kaur PJ, Singh D. Effects of a short term plyometric training program of agility in young basketball players. Brazil J Biomotri. 2011;5(4):271-8.

15. Maamer S, Karim C, Bianca M, Fabricio B. Del V, Foued C. Effects of Plyometric Training on Physical Fitness in Team Sport Athletes: A Systematic Review. J Hum Kinet. 2016 Dec 1; 53: 231-247.

16. Potteiger JA, Lockwood RH, Haub MD, Dolezal BA, Almuzaini KS, Schroeder JM, et al. Muscle power and fiber characteristics following 8 weeks of plyometric training. J. Strength Cond. Res.. 1999;13(3):275-9.

17. Parsons LS, Jones MT. Development of speed, agility, and quickness for tennis athletes. Stren Cond. J. 1998;20(3):149.

18. Renfro GJ. Summer plyometric training for football and its effect on speed and agility. Stren Cond. J. 1999;21(3):42.

19. Robinson BM, Owens B. Five-week program to increase agility, speed, and power in the preparation phase of a yearly training plan. Stren Cond. J. 2004;26(5):30-5. 
20. Potdevin FJ, Alberty ME, Chevutschi A, Pelayo P, Sidney MC. Effects of a 6-week plyometric training program on performances in pubescent swimmers. J. Strength Cond. Res. 2011;25(1):80-6.

21. Shaji J, Isha S. Comparative analysis of plyometric training program and dynamic stretching on vertical jump and agility in male collegiate basketball player. Al Ame en J Med Sci. 2009;2(1):36-46.

22. Behm DG, Wahl MJ, Button DC, Power KE, Anderson KG. Relationship between hockey skating speed and selected performance measures. J. Strength Cond. Res. 2005;19(2):326-31.
23. Saunders PU, Telford RD, Pyne DB, Peltola EM, Cunningham RB, Gore CJ, et al. Short-term plyometric training improves running economy in highly trained middle and long distance runners. J Stren Cond Res. 2006;20(4):947.

24. Thompson CJ, Cobb KM, Blackwell J. Functional training improves club head speed and functional fitness in older golfers. J. Strength Cond. Res. 2007;21(1):131-7.

Disclaimer: None to declare.

Conflict of Interest: None to declare.

Funding Sources: None to declare. 